\title{
Maternal and neonatal outcomes of placenta previa and accreta at Assiut women's health hospital, Egypt
}

\author{
Mahmoud S. Zakherah, Mervat Abdel-Aziz, Essam R. Othman, Ahmed M. Abbas*
}

Department of Obstetrics and Gynecology, Faculty of Medicine, Assiut University, Egypt

Received: 08 June 2018

Accepted: 03 July 2018

\section{*Correspondence:}

Dr. Ahmed M. Abbas,

E-mail: bmr90@hotmail.com

Copyright: (C) the author(s), publisher and licensee Medip Academy. This is an open-access article distributed under the terms of the Creative Commons Attribution Non-Commercial License, which permits unrestricted non-commercial use, distribution, and reproduction in any medium, provided the original work is properly cited.

\begin{abstract}
Background: The aim of the current study was to estimate the incidence of placenta previa (PP) and accreta (PA) in the period from January 2015 to December 2016 at Women's Health Hospital, Assiut University, Egypt and to evaluate the maternal and neonatal outcomes.

Methods: The study included all cases of PP with or without suspicion of accreta who were diagnosed preoperatively by ultrasound at Women's Health Hospital, Assiut University. Maternal and neonatal outcomes were evaluated. All intraoperative and postoperative data were reported. The obtained data was analyzed by means of SPSS software (version 22.0) and $\mathrm{p}<0.05$ was taken as the significant level.

Results: Total number of deliveries was 29027 cases. The number of cases of PP was 494 cases making an incidence of $1.7 \%$, among them 95 cases were confirmed during surgery to be accreta $(0.33 \%)$. Uterine artery ligation was carried out 300 cases $(60.7 \%)$ of cases while cesarean hysterectomy was performed in 56 cases $(11.3 \%)$. Bladder injury occurred in 58 cases $(11.7 \%)$, ureteric injury occurred in 6 cases $(1.2 \%)$, colon injury occurred in 1 case $(0.2 \%)$ and vascular injury occurred in 2 cases $(0.4 \%)$. Maternal mortality was 4 cases $(0.8 \%)$. The mean gestational age was $34.73 \pm 2.8$ weeks. Also, over the two years there were 148 neonatal cases $(29.9 \%)$ needed assisted ventilation in the form of ambu bag or endotracheal intubation gestation. NICU admission needed in 109 neonatal cases $(22.06 \%)$ and neonatal mortality reported in 18 neonates $(3.6 \%)$.

Conclusions: The incidence of both PP and PA is very high in our locality due to increase CS rate.
\end{abstract}

Keywords: Antepartum hemorrhage, Maternal morbidity, Placenta accreta, Placenta previa

\section{INTRODUCTION}

Placenta previa (PP) is an obstetric complication that occurs in the second and third trimesters of pregnancy. It may cause serious morbidity and mortality to both the fetus and the mother. It is one of the leading causes of vaginal bleeding in the second and third trimesters. ${ }^{1}$ Placenta previa complicates approximately $0.4 \%$ pregnant women and has a mortality rate of $0.03 \%$. $^{2,3}$

Placenta previa may be associated with placenta accreta (PA) or one of its more advanced forms as (placenta increta and percreta). Clinically, PA becomes problematic during delivery when the placenta does not completely separate from the uterus and is followed by massive obstetric hemorrhage, leading to disseminated intravascular coagulopathy; the need for hysterectomy; surgical injury to the ureters, bladder, bowel, or neurovascular structures; adult respiratory distress syndrome; acute transfusion reaction; electrolyte imbalance; and renal failure. ${ }^{4}$

In the period of 1982-2002, researchers have reported the incidence of PA as 1 in 533 deliveries. ${ }^{5}$ The marked increase in the incidence has been attributed to the 
increasing prevalence of cesarean delivery in the recent years.

The incidence of prenatal complications is also increased mainly due to preterm birth and small for gestational age fetuses, also the incidence of RDS in infants delivered at 30-35 weeks gestation by cesarean section was significantly higher in mothers with placenta previa than in women without PP. ${ }^{6,7}$ Placenta previa also was weakly but significantly associated with an increased risk of major congenital anomalies. ${ }^{8}$

The current study aims to evaluate the prevalence of cases of PP and PA attending to Women's Health Hospital Assiut University in the period from January 2015 to December 2016. Additionally, to evaluate the maternal and neonatal outcomes of PP and PA.

\section{METHODS}

The study was conducted at Women's Health Hospital; Assiut University included all cases delivered from January 2015 to December 2016 with PP which diagnosed preoperatively by ultrasound or postoperatively with or without PA. It was a prospective descriptive study. All cases were evaluated as regards history and examination, ultrasound report to knew if there is abnormal placentation as placenta accreta and its degree, hemoglobin and platelets levels before delivery.

The ultrasound finding criteria for confirmation of placenta previa was placental insertion totally or partially into the lower segment of the uterus. The color Doppler criteria suggestive of placenta accreta include: diffuse or focal lacunar flow, vascular lakes with turbulent flow, hypervascularity of serosa-bladder interface and markedly dilated vessels over peripheral sub placental zone. $^{4}$

\section{Maternal outcomes}

Type of cesarean section, amount of blood loss during the procedure, need for blood transfusion and type and amount of blood products, presence of abnormal placentation (accreta and increta or percreta), injury to nearby structures as bladder and colon or ureter and vascular injury, hysterectomy if done: total or subtotal, the need for additional surgical step as (uterine artery ligation, intra uterine balloon insertion, transverse BLynch, radiological intervention (IIAE) or cases with placenta left in situ.

Post-operative hemoglobin, post-partum hemorrhage, pelvic hematoma, ICU admission, need for blood transfusion, need for second operation, DVT or pulmonary embolism, post-operative infection, maternal mortality and duration of hospital stay were recorded.

\section{Neonatal outcomes}

Gestational age at time of delivery, birth weight, Apgar score at 1 minute and after 5 minutes, the need for assisted ventilation, congenital anomalies, NICU admission and neonatal mortality were recorded.

\section{Statistical analysis}

Data were processed using Statistical Package of Social Sciences version 22.0 (SPSS version 22.0 Inc., Chicago, IL, USA). Quantitative data were expressed as mean \pm standard deviation (SD) as appropriate. Qualitative data was expressed as frequency (numbers) and percentages. A probability value ( $p$-value) $<0.05$ was considered statistically significant.

\section{RESULTS}

The total number of deliveries during the 2-years study period was 29027 cases. Cases diagnosed as PP were 494 cases (1.7\%); of whom 95 cases $(19.2 \%)$ were proved to have a placenta accreta. Therefore, the incidence of PA was $0.4 \%$ among all deliveries.

Table 1: The baseline and pre-operative characteristics of the study participants.

\begin{tabular}{|ll|}
\hline Characteristics & $(\mathbf{n}=494)$ \\
\hline Age (years) & $30.7 \pm 2.8$ \\
\hline Weight (kg) & $77.5 \pm 5.5$ \\
\hline Parity ${ }^{\#}$ & $3(2-5)$ \\
\hline Previous CS & $2.9 \pm 0.8$ \\
\hline Gestational age (weeks) & $36.6 \pm 0.6$ \\
\hline Pulse & $80.2 \pm 5.0$ \\
\hline SBP & $120.1 \pm 2.5$ \\
\hline DBP & $78.7 \pm 3.1$ \\
\hline Pre-operative hemoglobin (gm/dl) & $10.88 \pm 0.67$ \\
\hline CS (cesarean section), SBP (Systolic Blood Pressure), DBP \\
(Diastolic Blood Pressure); all variables are presented as mean \\
and standard deviation; \# data are presented as median (range).
\end{tabular}

Table 2: Operative data of the study group.

\begin{tabular}{|ll|}
\hline \multicolumn{2}{|c|}{$\mathbf{N}(\%)$} \\
\hline Additional interventions & \\
\hline Uterine artery ligation & $300(60.7 \%)$ \\
\hline Leave placenta in situ & $3(0.6 \%)$ \\
\hline Intra uterine balloon insertion & $12(2.43 \%)$ \\
\hline Transverse B Lynch & $14(2.83 \%)$ \\
\hline Radiological intervention (*IIAE) & $6(1.21 \%)$ \\
\hline Cesarean hysterectomy & $56(11.34 \%)$ \\
\hline Blood transfusion & $468(94.7 \%)$ \\
\hline Injury to nearby structures & \\
\hline Bladder injury & $58(11.74 \%)$ \\
\hline Ureteric injury & $6(1.21 \%)$ \\
\hline Colon injury & $1(0.2 \%)$ \\
\hline Vascular injury & $2(0.4 \%)$ \\
\hline *IIAE: Internal iliac artery embolization & \\
\hline
\end{tabular}


Table 1 shows the baseline characteristics of the study participants.

Regarding the operative data of the patients, the most common additional surgical intervention needs was uterine artery ligation in 300 patients $(60.7 \%)$.

Cesarean hysterectomy was performed in 56 cases (11.74\%). The most common complication of surgery was bladder injury in 58 patients $(11.74 \%)$ (Table 2$)$.

Table 3: Post-operative data of the study group.

\begin{tabular}{|ll|}
\hline $\begin{array}{l}\text { Variables } \\
\text { (gm/dl) }\end{array}$ & Mean \pm SD or n $(\%)$ \\
\hline $\begin{array}{l}\text { Atonic Post-partum } \\
\text { hemorrhage }\end{array}$ & $9.47 \pm 1.25$ \\
\hline $\begin{array}{l}\text { Post-partum internal } \\
\text { hemorrhage }\end{array}$ & $7(0.4 \%)$ \\
\hline $\begin{array}{l}\text { Post-partum pelvic hematoma } \\
\text { Post-operative blood } \\
\text { transfusion }\end{array}$ & $2(0.4 \%)$ \\
\hline ICU admission & $105(21.26 \%)$ \\
\hline $\begin{array}{l}\text { Post-operative infection } \\
\text { Post-operative pulmonary } \\
\text { embolism }\end{array}$ & $35(7.09 \%)$ \\
\hline Re-intervention & $2(0.4 \%)$ \\
\hline - Just exploration & $1(0.2 \%)$ \\
\hline - $\quad$ Transverse B Lynch & $13(2.63 \%)$ \\
\hline - $\quad \begin{array}{l}\text { Intrauterine balloon } \\
\text { insertion }\end{array}$ & $3(0.61 \%)$ \\
\hline - $\quad$ Internal iliac artery ligation & $1(0.2 \%)$ \\
\hline - Hysterectomy & $2(0.4 \%)$ \\
\hline - $\quad$ Urological intervention & $1(0.2 \%)$ \\
\hline - $\quad \begin{array}{l}\text { Internal iliac artery } \\
\text { embolization }+\end{array}$ & $1(0.2 \%)$ \\
\hline $\begin{array}{l}\text { Post-operative duration of } \\
\text { hospital stays (days) }\end{array}$ & $3.34 \pm 3.13$ \\
\hline Maternal mortality & $4(0.8 \%)$ \\
\hline
\end{tabular}

Regarding the post-operative complications; atonic PPH was present in 2 cases $(0.4 \%)$, internal hemorrhage in 7 cases $(1.42 \%)$, pelvic hematoma in 2 cases $(0.4 \%)$, postoperative infection in 2 cases $(0.4 \%)$ and pulmonary embolism in one case.

Thirteen cases $(2.63 \%)$ needed re-intervention, two of them ended with hysterectomy. Maternal death occurred in 4 cases $(0.8 \%)$ (Table 3$)$.

The mean birth weight for neonates of all cases was $2758.8 \pm 554.09 \mathrm{gm}$. Ninety-one babies $(18.4 \%)$ required assisted ventilation and 109 babies $(22.1 \%)$ required admission to NICU. Finally, the neonatal mortality rate was $3.6 \%$ of cases (Table 4 ).
Table 4: Neonatal outcomes of the study group.

\begin{tabular}{|ll|}
\hline Variables & Mean \pm SD or n $(\%)$ \\
\hline Birth weight (grams) & $2758.8 \pm 554.09$ \\
\hline Apgar score at 1 min & $7.83 \pm 2.81$ \\
\hline Apgar score 5 mins & $8.96 \pm 2.39$ \\
\hline Assisted ventilation & $91(18.4 \%)$ \\
\hline *NICU admission & $109(22.1 \%)$ \\
\hline Congenital anomalies & $5(1.0 \%)$ \\
\hline Neonatal mortality & $18(3.6 \%)$ \\
\hline *NICU: Neonatal intensive care unit. & \\
\hline
\end{tabular}

\section{DISCUSSION}

Maternal and fetal morbidity and mortality from PP and PA represent a challenge to the obstetricians. With the rising incidence of caesarean sections combined with increasing maternal age, the number of cases of PP and its complications, will continue to increase. ${ }^{9}$

In the present study the incidence of PP was $1.7 \%$ that is higher than which reported $0.4 \% .^{2}$ Also the incidence of PA was $0.4 \%$ also higher than which reported $1 / 533$ deliveries. ${ }^{5}$ This alarming increase appears to be directly related to the rising rates of $\mathrm{CS}$ plus this risk increase with increase number of CS.

In the present study 468 cases $(94.7 \%)$ received blood transfusion intra operatively, there were some cases needed up to 15 units of blood. The present findings were similar to that of Warshak et al who reported that approximately $75 \%$ of patients required blood transfusion with a mean of $5.4 \pm 2.1$ units of RBCs. ${ }^{10}$ Thus, blood transfusion should be anticipated, and massive transfusion is not rare in these obstetric disasters.

In the present study 35 cases $(7.09 \%)$ needed ICU admission; this is in agreement with Eller et al, 2009 study who reported that ICU admissions are high in patients with PP and accreta. ${ }^{6}$ In present study bladder injury was occurred in 68 cases $(11.84 \%)$. Additionally, ureteric injury occurred in 6 cases $(1.21 \%)$. Also authors reported one case $(0.2 \%)$ of colonic injury and 2 cases $(0.4 \%)$ of vascular injury that is in agreement with Rosenberg et al. 2011 study who reported that surgical complications such as cystotomy, ureteric and vascular injury are more with PA. ${ }^{11}$ Additionally, these results were coincided with Alanwar et al, 2018 who reported the incidence of urinary tract injuries during CS with morbid adherence placenta was $21.7 \%$ (Bladder $11.7 \%$, Ureter $4.7 \%$, and bladder with ureter $5.3 \%) .{ }^{12}$ In rare cases, the placenta could invade beyond the abdominal viscera and reach the anterior abdominal wall. ${ }^{13}$

In the present study, the placenta left in situ in 3 cases of PA. All cases needed blood transfusions (up to 10 units) and one of them ended by post-operative uterine sepsis and ended by hysterectomy. Also these cases needed additional management in the form of uterine artery ligation, and massive antibiotic therapy, this is in contrast 
to Sentilhes et al, 2010 who reported that conservative management with leaving placenta in situ is an option and may decrease blood loss and other perioperative morbidity in select patients. ${ }^{14}$ However, authors agree with Timmerman et al., 2007 who chose to go ahead with a hysterectomy and reserve this management option only for patients who have minimal blood loss and strongly desire fertility preservation. ${ }^{15}$

In the present study uterine artery ligation was performed in 300 cases $(60.73 \%)$. this is in agreement with many authors who advocate routine uterine artery ligation in PA. ${ }^{16}$ Another study done at Tanta University Hospital which reported $100 \%$ success of double uterine artery ligation in management of PA. ${ }^{17}$ Others reported no value for this ligation. ${ }^{18}$ Mitwaly and his colleague tried a new method of combined surgical steps in management of PA. ${ }^{19}$ It was successful in 18 out of 20 cases for conservation of the uterus with no postpartum hemorrhage or maternal mortality. Other studies reported successful outcome for control of bleeding with the use of Foley's catheter balloon tamponade as a simple measure during $\mathrm{CS}^{20}$

In the present study cesarean hysterectomy was performed in 56 cases $(11.34 \%)$, that is similar to that reported by Wright et al, 2011 who found that hysterectomy is the most commonly performed procedure for the control of obstetric hemorrhage. ${ }^{21}$ Previous study in present hospital reported that abnormal placentation was the most second most common indication for peripartum hysterectomy $(21.9 \%)$ after uterine atony. ${ }^{22}$

In the present study maternal mortality occurred in 4 cases, 3 of them were accreta and one case previa nonaccreta. This is greater than which reported by Kim et al., 2013 who found that maternal mortality rate in cases of PP was $0.03 \% .^{23}$ That is may be due to the improper preparation for cases and may be due to most of cases come in an emergency state and the operation done by non-experience doctor. Moreover, the delayed decision to perform hysterectomy can be adding factor. In spite of the declining maternal mortality ratio in present hospital, postpartum hemorrhage still represents a major cause of maternal mortality and PP contributes significantly to those cases. ${ }^{24}$

In the present study congenital anomalies were reported in 5 neonatal cases $(1.0 \%)$. This is smaller than what is reported by Kancher et al, 2015 who found $6.2 \%$ of women with PP delivered a singleton infant with a major congenital malformation, compared with $3.8 \%$ of unaffected women. ${ }^{25}$ This is may be due to the sample size that was insufficient to detect the actual rates of congenital anomalies in these patients.

\section{CONCLUSION}

In conclusion, the incidence of both PP and PA is very high in present locality due to increase CS rate.
Funding: No funding sources

Conflict of interest: None declared

Ethical approval: The study was approved by the Institutional Ethics Committee

\section{REFERENCES}

1. Faiz AS, Ananth CV. Etiology and risk factors for placenta previa: an overview and meta-analysis of observational studies. J Matern Fetal Neonatal Med. 2003;13:175-90.

2. Kim LH, Caughey AB, Laguardia JC, Escobar GJ. Racial and ethnic differences in the prevalence of placenta previa. J Perinatol. 2012;32(4):260-4

3. Ananth CV, Smulian JC, Vintzileos AM. The effect of placenta previa on neonatal mortality: A population-based study in the United States, 1989 through 1997. Am J Obstet Gynecol. 2003;188(5):1299-304.

4. American Congress of Obstetricians and Gynecologists (2011 and 2015): Placenta accreta. Committee Opinion No. 266, January 2011 reaffirmed 2015 .

5. Wu S, Kocherginsky M, Hibbard JU. Abnormal placentation: twenty-year analysis. Am J Obstet Gynecol. 2005;192(5):1458-61.

6. Eller G, Porter TT, Soisson P, Silver RM. Optimal management strategies for placenta accreta. BJOG. 2009;116(5):648-54.

7. Bekku S, Mitsuda N, Ogita K, Suehara N, Fujimura $\mathrm{M}$, Aono T. High incidence of respiratory distress syndrome (RDS) in infants born to mothers with placenta previa. J Matern Fetal Med. 2000;9(2):1103 .

8. Kancherla V, Räisänen S, Gissler M, Kramer MR, Heinonen S. Placenta previa and risk of major congenital malformations among singleton births in Finland. Birth Defects Res A Clin Mol Teratol. 2015;103(6):527-35.

9. Royal College of Obstetrics and Gynecology. Green top Guideline No. 27 revised 2015: Placenta previa, placenta previa accreta and vasa previa diagnosis and management. RCOG. 2011. Available at https://www.rcog.org.uk/globalassets/documents/gui delines/gtg_27.pdf

10. Warshak CR, Ramos GA, Eskander R. Effect of predelivery diagnosis in 99 consecutive cases of placenta accreta. Obstet Gynecol. 2010;115(1):65-9.

11. Shellhaas CS, Gilbert S, Landon MB, Varner MW, Leveno KJ, Hauth JC, et al. The frequency and complication rates of hysterectomy accompanying cesarean delivery. Obstet Gynecol. 2009 Aug;114(2 Pt 1):224.

12. Alanwar A, Al-Sayed HM, Ibrahim AM, Elkotb AM, Abdelshafy A, Abdelhadi R, et al. Urinary tract injuries during cesarean section in patients with morbid placental adherence: retrospective cohort study. J Maternal Fetal Neonat Med. 2018 (Article in press). 
13. Abbas AM, Ali SEEA, Michael A, Ali SS. Successful fertility-preserving management of a case of placenta percreta invading the urinary bladder and anterior abdominal wall: A case report. Middle East Fertil Soc J. 2018;23(1):77-80.

14. Sentilhes L, Ambroselli C, Kayem G, Provansal M, Fernandez H, Perrotin F, et al. Maternal outcome after conservative treatment of placenta accreta. Obstet Gynecol. 2010;115:26-34.

15. Timmermans S, van Hof AC, Duvekot JJ. Conservative management of abnormally invasive placentation. Obstet Gynecol Surv. 2007;62:529-39.

16. Shabana A, Fawzy M, Refaie W. Conservative management of placenta percreta: a stepwise approach. Arch Gynecol Obstet. 2015;291(5):993-8.

17. Shehata A, Hussein N, El-Halwagy A, El Gergawy A. Could Simple Procedures Minimize Hysterectomy in Management of Placenta Accreta? Ind J Obstet Gynaecol Res. 2015;2(4):213-7.

18. Iwata A1, Murayama Y, Itakura A, Baba K, Seki H, Takeda S. Limitations of internal iliac artery ligation for the reduction of intraoperative hemorrhage during cesarean hysterectomy in cases of placenta previa accreta. J Obstet Gynaecol Res. 2010;36(2):254-9.

19. Mitwaly AA, Abbas AM. Sequential surgical steps for conservative management of morbidly adherent placenta: case series. Thai J Obstet Gynecol. 2016;24:136-40.

20. Ali MK, Abbas AM, Abdelbadee AY, Shazly SA, Abdel Magied AM. Use of Foley's catheter balloon tamponade to control placental site bleeding resulting from major placenta previa during cesarean section. Proc Obstet Gynecol. 2016;6(3):4.
21. Wright JD, Devine P, Shah M, Gaddipati S, Lewin SN, Simpson LL, et al. Morbidity and mortality of peripartum hysterectomy. Obstet Gynecol. 2010;115:1187-93.

22. Abbas AM, Abdelbadee AY, Amin MT, Abdelrahman RM, Tolba SM, Abdelkarim AR, et al. Emergency peripartum hysterectomy in a tertiary hospital in Upper Egypt: six years analysis. Int $\mathbf{J}$ Reprod Contracept Obstet Gynecol. 2016;5(4):953-8.

23. Kim TH, Lee HH, Kwak JJ. Conservative management of abnormally invasive placenta: choriocarcinoma with uterine arteriovenous fistula from remnant invasive placenta. Acta Obstet Gynecol Scand. 2013; 92(8):989-90.

24. Abbas AM, Amin MT, Ali SS, Salem NZ. Maternal mortality: a tertiary care hospital experience in Upper Egypt. Int $\mathbf{J}$ Reprod Contracept Obstet Gynecol. 2016;5(5):1466-71.

25. Kanchert V, Raisanen S, Gissier M, Kramer MR, Heinonen S. Placenta previa and risk of major congenital malformation among singleton births in Finland Birth Defects. Res A Clin Mol Teratol. 2015:103(6):527-35.

Cite this article as: Zakherah MS, Aziz AA, Othman ER, Abbas AM. Maternal and neonatal outcomes of placenta previa and accreta at Assiut women's health hospital, Egypt. Int J Reprod Contracept Obstet Gynecol 2018;7:3024-8. 